CAMPAGNOL R; MATSUZAKI RT; MELLO SC. 2016. Condução vertical e densidade de plantas de minimelancia em ambiente protegido. Horticultura Brasileira 34: 137-143. DOI - http://dx.doi.org/10.1590/S0102-053620160000100021

\title{
Condução vertical e densidade de plantas de minimelancia em ambiente protegido
}

\author{
Rafael Campagnol; Ricardo T Matsuzaki; Simone C Mello \\ Escola Sperior de Agricultura Luiz de Queiroz (ESALQ), Piracicaba-SP, Brasil; rcampagnol@usp.br; ricardo.matsuzaki@usp.br; \\ scmello@usp.br
}

\begin{abstract}
RESUMO
O consumo de produtos diferenciados como hortaliças em miniatura vem crescendo nos últimos anos. Esse nicho de mercado é de grande interesse dos horticultores por alcançar maior remuneração comparado aos produtos tradicionais. Exemplo desse produto é a minimelancia, que vem sendo cultivada não somente em campo, mas também em estufas agrícolas. Nesse último sistema, as plantas devem ser cultivadas no sentido vertical e podadas. Desta forma, objetivou-se verificar a influência de três sistemas de condução (S1= uma haste e um fruto por planta conduzido na haste principal; S2= uma haste e um fruto por planta conduzido na haste secundária; e S3= duas hastes e um fruto por planta conduzido na haste principal) e duas densidades de plantas $\left(2,4\right.$ e 4,8 plantas $\left./ \mathrm{m}^{2}\right)$ sobre as características vegetativas, produtivas e qualitativas de minimelancia cultivada no sistema vertical. A condução das plantas com duas hastes e um fruto elevou a produtividade por área, sem diferir do S1. Para esse sistema de condução, a densidade de cultivo de 4,8 plantas $/ \mathrm{m}^{2}$ elevou a produtividade em aproximadamente duas vezes a alcançada pela densidade de 2,4 plantas $/ \mathrm{m}^{2}$, contudo, com redução de $12,5 \%$ na massa média dos frutos. Independente da densidade de cultivo e do sistema de condução de plantas utilizados, os frutos apresentaram qualidade adequada para a comercialização e as produtividades foram de 2 a 4 vezes superiores à média nacional de melancia cultivada no sistema rasteiro.
\end{abstract}

Palavras-chave: Citrullus lanatus, poda, cultivo vertical, cultivo protegido.

\begin{abstract}
Vertical conduction system and plant density of mini watermelon in greenhouse

The consumption of differentiated products increased during the last years. This niche of market is of great interest by growers to achieve higher returns compared to traditional products. One example is the mini watermelon, which is grown not only under field, but also under greenhouse conditions. Plants under greenhouse must be conducted vertically and pruned. This research aimed to investigate the influence of three conducing systems $(\mathrm{S} 1=$ one stem and one fruit per plant attached to the main stem; $\mathrm{S} 2=$ one stem and one fruit per plant attached to the secondary stem, and S3= two stems per plant and one fruit attached to the main stem) and two plant densities $\left(2.4\right.$ and 4.8 plants $\left./ \mathrm{m}^{2}\right)$ on the vegetative, productive and qualitative characteristics of mini watermelon grown in the vertical system. The plant conduction system with two stems and one fruit increased yield of fruit, without differing from S1. For this system, the increased density of 4.8 plants $/ \mathrm{m}^{2}$ increased yield by approximately twice the density of 2.4 plants $/ \mathrm{m}^{2}$, but it caused $12.5 \%$ of reduction on average fruit weight. Regardless of plant density and conduction system, fruits presented adequate quality for marketing and yield corresponding to 2 to 4 times the national average for watermelon grown in the traditional system.
\end{abstract}

Keywords: Citrullus lanatus, pruning, vertical conduction, greenhouse cultivation.

(Recebido para publicação em 22 de maio de 2014; aceito em 31 de julho de 2015)

(Received on May 22, 2014; accepted on July 31, 2015)

$\mathrm{O}$ mercado de hortaliças é bastante dinâmico e fortemente influenciado pela preferência dos consumidores, sendo que nos últimos anos observou-se uma crescente demanda por produtos diferenciados quanto ao tamanho, coloração, forma e aroma (Purquerio \& Melo, 2011).

Como exemplo, é possível citar o aumento do consumo de hortaliças de tamanho reduzido como as minimelancias, melões e tomates, bem como as hortaliças minimamente processadas, higienizadas e acondicionadas em embalagens, que prolongam a vida pós-colheita dos produtos, além de serem práticas e atrativas.

As minimelancias adequam-se às mudanças da sociedade brasileira, com famílias cada vez menores (IBGE, 2014). Seus frutos apresentam peso de 1,5 a $4 \mathrm{~kg}$, suficientes para o consumo de 2 a 4 pessoas e podem ser facilmente armazenados nos refrigeradores, ao con- trário dos grandes frutos das cultivares de melancias tradicionais, que pesam de 6 a $15 \mathrm{~kg}$. Além de se diferenciarem pelo seu tamanho reduzido, algumas cultivares produzem frutos de polpa amarela e outras não apresentam sementes. Com isso, as minimelancias visam atender a demanda cada vez maior do mercado de hortaliças por produtos que ofereçam maior qualidade, palatabilidade, saudabilidade e praticidade (FIESP \& ITAL, 2010). 
Apesar de também ser cultivada em campo, a minimelancia apresenta grande potencial produtivo em casa-de-vegetação, tanto no verão quanto no inverno, dependendo do manejo dos fatores ambientais. Nesse ambiente, como forma de aumentar a eficiência do uso da área, as plantas são conduzidas no sistema vertical, o que pode gerar uma produtividade três vezes superior à obtida em cultivos rasteiros. Contudo, para que isso seja atingido, devem ser realizados manejos culturais específicos, como poda e condução das plantas, e utilizar uma densidade de plantas que proporcione o melhor retorno econômico ao produtor.

A prática da poda e da condução de plantas criam condições para a maximização da produção de frutos de alta qualidade pelo estabelecimento do número ideal de frutos e seu posicionamento na planta, da melhor arquitetura da planta, promovendo o balanço entre fonte e dreno de acordo com as necessidades produtivas (Papadopoulos, 1994). Além disso, a condução das plantas no sentido vertical facilita a aplicação de defensivos, a ventilação entre as plantas, a distribuição da radiação solar sobre o dossel e possibilita o aumento da densidade de plantas, gerando maior número de frutos por área (Silva et al., 1998).

$\mathrm{O}$ adensamento das plantas pode elevar a produtividade. Entretanto, também pode reduzir o tamanho dos frutos (Kultur et al., 2001; Goreta et al., 2005). A densidade de plantas ideal, do ponto de vista agronômico, é aquela que promoverá a máxima alocação de massa seca para os frutos, sendo isso alcançado quando a planta possui uma área foliar que permita a máxima interceptação de radiação solar e equilíbrio entre as partes vegetativa e reprodutiva da planta (Schvambach et al., 2002). Em minimelancia, o aumento da densidade pode reduzir a área foliar do terço médio e superior da planta e a interceptação da radiação solar pelas folhas da porção inferior, o que resulta em decréscimo da sua eficiência fotossintética e, consequentemente, da quantidade de fotoassimilados direcionados aos frutos (Watanabe et al., 2003).

Assim, o objetivo deste trabalho foi estudar os efeitos de sistemas de con- dução de plantas e densidade de cultivo sobre a produtividade e as características físico-químicas de minimelancia cultivada em ambiente protegido.

\section{MATERIAL E MÉTODOS}

O experimento foi conduzido de 20 de outubro de 2008 a 16 de janeiro de 2009 na área experimental do Departamento de Produção Vegetal, pertencente à Escola Superior de Agricultura "Luiz de Queiroz", no município de Piracicaba-SP. Segundo a classificação climática proposta por Köppen, o clima é do tipo Cwa, ou seja, subtropical úmido com três meses mais secos (junho, julho e agosto), chuvas de verão, seca no inverno, temperatura do mês mais quente superior a $22^{\circ} \mathrm{C}$ e a do mês mais frio inferior a $18^{\circ} \mathrm{C}$.

O solo utilizado no cultivo, Nitossolo Vermelho Eutrófico Típico, apresentou os seguintes resultados da análise química: matéria orgânica (dicromato de potássio $)=31 \mathrm{mg} / \mathrm{dm}^{3} ; \mathrm{P}($ resina $)=$ $312 \mathrm{mg} / \mathrm{dm}^{3} ; \mathrm{K}^{+}$(resina) $=15,6 \mathrm{mmolc} /$ $\mathrm{dm}^{3} ; \mathrm{Ca}^{2+}$ (resina) $=89 \mathrm{mmolc} / \mathrm{dm}^{3} ; \mathrm{Mg}^{2+}$ $($ resina $)=36 \mathrm{mmolc} / \mathrm{dm}^{3} ; \mathrm{pH}\left(\mathrm{CaCl}_{2}\right)=$ 6,$1 ; \mathrm{S}=90 \mathrm{mg} / \mathrm{dm}^{3} ; \mathrm{CTC}=160,6 \mathrm{mmolc} /$ $\mathrm{dm}^{3} ; \mathrm{V} \%=88 ; \mathrm{B}$ (água quente) $=0,84$ $\mathrm{mg} / \mathrm{dm}^{3}$.

A casa-de-vegetação agrícola utilizada foi do tipo arco, com 7,0 m de largura, $40 \mathrm{~m}$ de comprimento e coberta com filme de polietileno aditivado (anti-UV) com $150 \mu \mathrm{m}$ de espessura. A altura na parte central foi de $4,5 \mathrm{~m}$ e pé direito de $2,8 \mathrm{~m}$. As médias das temperaturas máximas, mínimas, médias e umidade relativa, durante o período de cultivo, registradas por meio de um datalogger foram de $42,1,18,3,27^{\circ} \mathrm{C}$ e $53,8 \%$, respectivamente.

Utilizou-se o híbrido de melancia Smile, caracterizado por frutos com massa entre 1,5 e $2,5 \mathrm{~kg}$ e ciclo produtivo de 35 a 40 dias após a antese. Foram realizadas fertirrigações diárias com soluções nutritivas aplicadas para cada fase de desenvolvimento das plantas. As fases I, II e III corresponderam aos períodos do transplante das mudas à antese, da antese até o início do desenvolvimento dos frutos e do início do desenvolvimento dos frutos até a colheita, respectivamente. As quantidades de fertilizantes utilizadas nas fases I, II e III foram, respectivamente, de 180,$5 ; 201,5$ e $500,0 \mathrm{mg} / \mathrm{L}$ de nitrato de potássio ( $13 \%$ de $\mathrm{N}$ e $44 \%$ de $\mathrm{K}_{2} \mathrm{O}$ ); 380,$0 ; 426,0$ e $300,0 \mathrm{mg} / \mathrm{L}$ de nitrato de cálcio ( $15 \%$ de $\mathrm{N}$ e $20 \%$ de Ca); 50,0 ; 100,0 e $0,0 \mathrm{mg} / \mathrm{L}$ de nitrato de amônio $(33 \%$ de N);230,0; 257,0 e $80,0 \mathrm{mg} / \mathrm{L}$ de fosfato monoamônico ( $10 \%$ de $\mathrm{Ne} 52 \%$ de $\left.\mathrm{P}_{2} \mathrm{O}_{5}\right) ; 190,0 ; 210,0$ e $140,0 \mathrm{mg} / \mathrm{L}$ de sulfato de magnésio $(9,5 \%$ de $\mathrm{Mg}$ e $12 \%$ de $\mathrm{S}) ; 192,0 ; 192,0$ e $381,0 \mathrm{mg} / \mathrm{L}$ de sulfato de potássio $\left(50 \%\right.$ de $\mathrm{K}_{2} \mathrm{O}$ e $18 \%$ de $\mathrm{S}$ ); e 10,$0 ; 15,0$ e $15,0 \mathrm{mg} / \mathrm{L}$ de um produto comercial composto por micronutrientes $(1,5 \%$ de $\mathrm{B}, 0,5 \%$ de $\mathrm{Cu}, 3,4 \%$ de $\mathrm{Fe}, 3,2 \%$ de $\mathrm{Mn}, 0,1 \%$ de Mo, $4,2 \%$ de Zn, $12 \%$ de K, $1,2 \%$ de $\mathrm{Mg}$ e $1,5 \%$ de $\mathrm{S}$ ).

O sistema de irrigação foi composto por gotejadores autocompensantes com vazão de $1,0 \mathrm{~L} / \mathrm{h}$. A quantidade de água aplicada por irrigação foi calculada com base nas leituras obtidas nos tensiômetros instalados a 15 e $30 \mathrm{~cm}$ de profundidade, próximos às plantas, cuja tensão limite de água no solo foi de $20 \mathrm{kPa}$, conforme descrito por Marouelli (2008).

Os tratamentos foram compostos por três sistemas de condução (S1= uma haste e um fruto por planta conduzido na haste principal; $\mathrm{S} 2=$ uma haste e um fruto por planta conduzido na haste secundária; e S3= duas hastes e um fruto por planta conduzido na haste principal) e duas densidades de plantas $(2,4$ e 4,8 plantas $/ \mathrm{m}^{2}$ ). O espaçamento entre plantas na linha foi de 30 e $60 \mathrm{~cm}$ para os tratamentos com 2,4 e 4,8 plantas/ $\mathrm{m}^{2}$, respectivamente. A parcela útil foi composta por 16 plantas, excluindo as bordaduras.

O delineamento experimental foi em blocos casualizados, com quatro repetições, e seis tratamentos dispostos no esquema fatorial $3 \times 2$, ou seja, três sistemas de condução e duas densidades de plantas.

As mudas foram produzidas em bandejas de poliestireno expandido de 200 células preenchidas com substrato fibra de coco. Elas foram transplantadas aos 40 dias após a semeadura (DAS) para os canteiros cobertos com plástico preto no espaçamento de $50 \mathrm{~cm}$ entre linhas e 90 $\mathrm{cm}$ entre linhas duplas. 
A estrutura de condução das plantas foi composta por mourões de madeira de 3,0 m de comprimento a partir do solo, arames de aço e fitilhos plásticos com proteção contra raios ultravioleta. Os arames de aço foram passados pelos mourões de madeira a 1,5 e 2,9 m de altura, sendo o superior utilizado para sustentar os fitilhos plásticos e o inferior para amarrar as redes de nylon que sustentaram os frutos.

Após a emissão da quarta folha definitiva, as hastes das plantas foram enroladas nos fitilhos e, assim, conduzidas no sentido vertical. Nos tratamentos $\mathrm{S} 1$ e S2, as ramificações secundárias originadas abaixo do terceiro internódio foram eliminadas.

Para o tratamento S1, a planta foi conduzida com uma haste principal, sendo as ramificações secundárias podadas logo após a emissão da terceira folha. No tratamento $\mathrm{S} 2$, a planta também foi conduzida com uma haste principal; contudo, o fruto foi conduzido em uma das hastes secundárias. Depois da fixação do fruto na haste secundária, esta foi podada após o aparecimento da folha subsequente. As demais ramificações foram podadas após a terceira folha.

No tratamento S3, as plantas foram conduzidas com duas hastes no sentido vertical, sendo uma a haste principal e a outra a primeira ramificação secundária que surgiu abaixo do terceiro internódio. As ramificações originadas dessas duas hastes foram podadas após a terceira folha. Nos tratamentos S1 e S3 os frutos foram conduzidos na haste principal entre o $8^{\circ}$ e o $14^{\circ}$ internódio. Já no tratamento $\mathrm{S} 2$, eles foram mantidos em uma das hastes secundárias originadas das axilas foliares localizadas entre $\mathrm{O}$ $8^{\circ}$ e o $14^{\circ}$ internódio da haste principal. Foi mantido apenas um fruto por planta e a poda da haste principal foi realizada a 2,2 $\mathrm{m}$ de altura para todos os tratamentos.

As polinizações foram feitas manualmente no período matutino (entre 8 e 10 horas). Elas iniciaram aos 34 DAT para os tratamentos $\mathrm{S} 1$ e $\mathrm{S} 3$ e aos 42 DAT para o tratamento S2. Essa operação foi realizada diariamente até que todas as flores femininas que surgiram entre o $8^{\circ}$ e o $14^{\circ}$ internódio, para S1 e $\mathrm{S} 3$, e as primeiras flores femininas dos ramos secundários para o tratamento $\mathrm{S} 2$, fossem polinizadas. Nesse caso, após a polinização, o ramo foi podado depois do surgimento de uma folha, após a emissão da flor.

Garantida a fixação dos frutos na posição desejada, os demais foram eliminados, deixando-se apenas um fruto por planta. No tratamento S2, onde os frutos foram conduzidos nas hastes secundárias, após a seleção dos frutos, os demais ramos secundários, que também tinham frutos, foram mantidos com três folhas.

Os frutos fixados, quando atingiram aproximadamente $4,0 \mathrm{~cm}$ de diâmetro, foram sustentados através de redes (sacolas) de nylon, que foram amarradas nos arames horizontais que seguiam acima da linha de plantio.

A colheita dos frutos foi realizada quando atingiram seu tamanho máximo, perderam o brilho característico e mudaram a textura de sua casca (Almeida, 2006). Foram realizadas três colheitas, aos 81,85 e 89 dias após o transplante (DAT). A quantidade de frutos colhidos em cada colheita variou em função da época de polinização das flores. Nos tratamentos S1, S2 e S3 foram colhidos, respectivamente, 45,$8 ; 15,3$ e 43,3\% dos frutos na primeira colheita, 52,3; 51,2 e $55,5 \%$ na segunda e 1,$9 ; 33,4$ e $1,2 \%$ na terceira.

As características avaliadas foram a massa seca dos ramos (MSR), dos pecíolos (MSP), das folhas (MSF) e total (MST); área foliar (AF), área foliar específica (AFE) e índice de área foliar (IAF); massa média dos frutos (MMF); produtividade total (PT); produtividade comercial (PC); comprimento médio $(\mathrm{CMF})$, diâmetro médio (DMF) e índice de formato dos frutos (IFF); firmeza da polpa (FIR); teor de sólidos solúveis (SS); teor de ácido ascórbico (AA); acidez titulável (AT); pH e relação $\mathrm{SS}$ / AT do fruto.

A determinação da massa seca da parte vegetativa da planta foi realizada coletando-se quatro plantas por parcela no período da colheita. Cada planta foi separada em limbo foliar, pecíolos e hastes e secadas em estufa com circulação forçada de ar a $65^{\circ} \mathrm{C}$, até obtenção de peso constante. A MST foi composta pela somatória das massas das diferentes partes da planta.

Os limbos foliares foram utilizados para determinação da $\mathrm{AF}$ ( $\mathrm{cm}^{2} /$ planta), antes de serem secos, por um integrador de área LI-COR (modelo LI 300). A $\operatorname{AFE}\left(\mathrm{cm}^{2} / \mathrm{g}\right)$ foi calculada pela razão entre a AF e a MSF. O IAF foi determinado pela razão entre a $\mathrm{AF}$ e a área destinada a cada planta no solo, de acordo com o espaçamento entre plantas.

Para determinação das características produtivas, 12 frutos por parcela foram coletados, medidos e pesados para a determinação do $\mathrm{CMF}, \mathrm{DMF}$, MMF e PT. O comprimento foi obtido no sentido longitudinal e o diâmetro no sentido equatorial dos frutos. O IFF foi calculado por meio da razão entre o CMF e o DMF.

Depois de pesados e medidos, quatro frutos por parcela foram obtidos aleatoriamente e seccionados no sentido longitudinal, sendo uma parte utilizada para a determinação da FIR e a outra homogeneizada por meio de um processador de alimentos para a determinação das demais características qualitativas dos frutos.

A FIR foi determinada pela média de três leituras realizadas por um penetrômetro manual com ponteira de 8 $\mathrm{mm}$ na região central dos frutos cortados no sentido longitudinal. O SS foi determinado por leitura direta na polpa homogeneizada de cada fruto, com um refratômetro digital (marca Atago, modelo PR-32 $\alpha$ ).

Para a determinação do AA, $10 \mathrm{~g}$ da polpa homogeneizada foram diluídos em $90 \mathrm{~mL}$ de ácido oxálico a 1\%. A titulação foi feita com solução de 2,6-diclorofenol-indofenol (Carvalho et al., 1990). A AT foi determinada usando-se $10 \mathrm{~g}$ da polpa homogeneizada, que foram diluídos em $90 \mathrm{~mL}$ de água destilada. A titulação foi feita com hidróxido de sódio $0,05 \mathrm{~N}$ até que a solução atingisse $\mathrm{pH}$ igual a 8,1, através de um pHmetro digital (Tec-3MP) (Carvalho et al., 1990). O pH foi obtido por leitura direta na polpa homogeneizada. A relação SS/AT, parâmetro que indica o estado de maturação e sabor dos frutos, foi obtida pela razão entre SS e AT (Chitarra \& Chitarra, 2005).

Para todas as variáveis estudadas realizou-se o teste de Shapiro-Wilk, a 
fim de verificar a distribuição normal ou não dos dados (se p-valor $>0,05$ ), e o teste de Bartlett, para verificar a homogeneidade de variância. Posteriormente, os resultados foram submetidos à análise de variância e as médias comparadas pelo teste de Tukey a $5 \%$ de probabilidade, por meio do programa estatístico AgroEstat.

\section{RESULTADOS E DISCUSSÃO}

\section{Características vegetativas}

Houve interação entre sistemas de condução e densidade de plantas somente para o IAF, cujo maior valor $(2,0)$ foi observado para o sistema S2, seguido dos sistemas S3 $(1,79)$ e S1 $(1,46)$, todos na densidade de 4,8 plantas $/ \mathrm{m}^{2}$. Na menor densidade de plantas, não houve diferença significativa entre os sistemas de condução, sendo que, na média, os valores foram $46,4 \%$ inferiores aos obtidos na maior densidade de cultivo. Os valores de IAF foram semelhantes aos obtidos por Duarte \& Peil (2010) em melão e inferiores aos alcançados por Peil (2000) em pepino, ambas as culturas tutoradas e pertencentes à mesma família botânica.

O sistema de condução S2 elevou a MSR e MST em relação aos sistemas S1 e S3 (Tabela 1). Esse fato ocorreu, porque a polinização das plantas no sistema S2 foi realizada oito dias após a polinização das plantas nos sistemas $\mathrm{S} 1$ e S3. Assim, as plantas em S2 tiveram mais tempo para aumentar sua massa vegetal, principalmente de ramos, antes do fruto tornar-se o maior dreno dos fotoassimilados. Em melancia, assim como em melão, o fruto é o principal dreno de fotoassimilados (Duarte et al., 2008), reduzindo, dessa forma, a alocação de nutrientes para outras partes da planta como folhas, caule e brotações.

A MSR, MSF e MST também foram influenciadas pela densidade de cultivo, cujos valores foram superiores na densidade de 2,4 plantas $/ \mathrm{m}^{2}$. Os valores de AF não diferiram significativamente entre as densidades de plantas. AAFE, por sua vez, foi menor na menor densidade de plantas pelo fato da MSF ter sido maior nessa densidade, uma vez que esse parâmetro representa a relação entre a $\mathrm{AF}$

Tabela 1. Massa seca dos ramos (MSR), massa seca dos pecíolos (MSP), massa seca do limbo foliar (MSF), massa seca total (MST), área foliar (AF) e área foliar específica (AFE) de minimelancia 'Smile' em função do sistema de condução (S) e da densidade de plantas (D) \{dry matter of stems (MSR), dry matter of petioles (MSP), dry matter of leaf limbs (MSF), total dry matter (MST), leaf area (AF) and specific leaf area (AFE) of mini watermelon plants 'Smile' at the time of fruit harvest according to the conduction system (S) and plant density (D)\}. Piracicaba, ESALQ, 2008/2009.

\begin{tabular}{|c|c|c|c|c|c|c|}
\hline \multirow{2}{*}{ Tratamentos } & MSR & MSP & MSF & MST & \multirow{2}{*}{$\begin{array}{c}\mathrm{AF}\left(\mathrm{cm}^{2} /\right. \\
\text { planta) }\end{array}$} & \multirow{2}{*}{$\begin{array}{c}\mathrm{AFE} \\
\left(\mathrm{cm}^{2} / \mathrm{g}\right)\end{array}$} \\
\hline & \multicolumn{4}{|c|}{ (g) } & & \\
\hline \multicolumn{7}{|c|}{ S (sistema de condução) ${ }^{1}$} \\
\hline$\overline{S 1}$ & $10,40 \mathrm{~b}$ & $2,33 b$ & $23,29 b$ & $36,01 \mathrm{c}$ & $3485,46 b$ & $149,69 \mathrm{a}$ \\
\hline S2 & $16,63 \mathrm{a}$ & $3,19 \mathrm{a}$ & $30,59 a$ & $50,41 \mathrm{a}$ & $4484,81 \mathrm{a}$ & $146,62 \mathrm{a}$ \\
\hline $\mathrm{S} 3$ & $12,96 \mathrm{~b}$ & $2,78 \mathrm{ab}$ & $27,40 \mathrm{a}$ & $43,14 b$ & $4263,77 \mathrm{a}$ & $155,63 \mathrm{a}$ \\
\hline \multicolumn{7}{|c|}{$\mathrm{D}$ [densidade de plantas $\left.\left(\mathrm{pl} / \mathrm{m}^{2}\right)\right]$} \\
\hline 4,8 & $12,08 \mathrm{~b}$ & $2,67 \mathrm{a}$ & $24,45 b$ & $39,20 \mathrm{~b}$ & $3936,16 a$ & $161,00 \mathrm{a}$ \\
\hline 2,4 & $14,58 \mathrm{a}$ & $2,86 \mathrm{a}$ & $29,73 \mathrm{a}$ & $47,17 \mathrm{a}$ & $4219,87 \mathrm{a}$ & $141,93 \mathrm{~b}$ \\
\hline$\overline{C V}(\%)$ & 15,09 & 19,92 & 11,59 & 12,58 & 9,50 & 6,81 \\
\hline
\end{tabular}

Médias seguidas pela mesma letra na coluna não diferem entre si pelo teste de Tukey a 5\% (means followed by the same letter in the column do not differ by Tukey test at $5 \%$ ); ${ }^{1} \mathrm{~S} 1=$ plantas conduzidas com uma haste e um fruto por planta conduzido na haste principal; $\mathrm{S} 2=$ plantas conduzidas com uma haste e um fruto por planta conduzido na haste secundária; e $\mathrm{S} 3=$ plantas conduzidas com duas hastes e um fruto por planta conduzido na haste principal $(\mathrm{S} 1=$ plants conducted with one stem and one fruit per plant attached to the main stem; $\mathrm{S} 2=$ plants conducted with one stem and one fruit per plant attached to the secondary stem, and $\mathrm{S} 3=$ plants conducted with two stems per plant and one fruit attached to the main stem).

Tabela 2. Massa média dos frutos (MMF), produtividade total (PT), comprimento médio dos frutos (CMF), diâmetro médio dos frutos (DMF) e índice de formato do fruto (IFF) de minimelancia 'Smile' em função do sistema de condução (S) e da densidade de plantas (D) \{average fruit weight (MMF), total yield (PT), average fruit lenght (CMF) average fruit diameter (DMF) and fruit shape index (IFF) of mini watermelon 'Smile' depending on the conduction system (S) and plant density (D)\}. Piracicaba, ESALQ, 2008/2009.

\begin{tabular}{|c|c|c|c|c|c|c|c|c|}
\hline \multirow{2}{*}{ Tratamentos } & \multirow{2}{*}{$\begin{array}{c}\text { MMF } \\
\text { (kg/fruto) }\end{array}$} & \multirow{2}{*}{\multicolumn{2}{|c|}{$\begin{array}{c}\text { PT } \\
\text { (t/ha) }\end{array}$}} & \multicolumn{2}{|c|}{ CMF } & \multicolumn{2}{|c|}{ DMF } & \multirow{2}{*}{ IFF } \\
\hline & & & & \multicolumn{4}{|c|}{$(\mathrm{cm})$} & \\
\hline \multicolumn{9}{|c|}{ S (sistema de condução) ${ }^{1}$} \\
\hline S1 & $1,84 \mathrm{~b}$ & 60,28 & $\mathrm{~b}$ & 15,85 & $\mathrm{~b}$ & 15,12 & $\mathrm{~b}$ & $1,05 \mathrm{~b}$ \\
\hline $\mathrm{S} 2$ & $2,05 \mathrm{ab}$ & 66,80 & $\mathrm{ab}$ & 16,52 & $\mathrm{ab}$ & 15,15 & $\mathrm{~b}$ & 1,09 a \\
\hline $\mathrm{S} 3$ & 2,19 a & 71,06 & $\mathrm{a}$ & 16,93 & $\mathrm{a}$ & 16,13 & $\mathrm{a}$ & $1,05 \mathrm{~b}$ \\
\hline \multicolumn{9}{|c|}{$\mathrm{D}$ [densidade de plantas $\left.\left(\mathrm{pl} / \mathrm{m}^{2}\right)\right]$} \\
\hline 4,8 & $1,89 \mathrm{~b}$ & 84,20 & a & 16,13 & $\mathrm{~b}$ & 15,15 & $\mathrm{~b}$ & $1,07 \quad a$ \\
\hline 2,4 & 2,16 a & 47,89 & $\mathrm{~b}$ & 16,74 & a & 15,79 & $\mathrm{a}$ & 1,06 a \\
\hline $\mathrm{CV}(\%)$ & 9,97 & 10,32 & & 3,63 & & 2,74 & & 2,76 \\
\hline
\end{tabular}

Médias seguidas pela mesma letra na coluna não diferem entre si pelo teste de Tukey a 5\% (means followed by the same letter in the column do not differ by Tukey test at $5 \%$ ); ${ }^{1} \mathrm{~S} 1=$ plantas conduzidas com uma haste e um fruto por planta conduzido na haste principal; S2= plantas conduzidas com uma haste e um fruto por planta conduzido na haste secundária; e $\mathrm{S} 3=$ plantas conduzidas com duas hastes e um fruto por planta conduzido na haste principal $(\mathrm{S} 1=$ plants conducted with one stem and one fruit per plant attached to the main stem; $\mathrm{S} 2=$ plants conducted with one stem and one fruit per plant attached to the secondary stem, and $\mathrm{S} 3=$ plants conducted with two stems per plant and one fruit attached to the main stem).

e MSF (Tabela 1). Esse fato pode ser explicado pelo acúmulo de fotoassimilados nas folhas das plantas cultivadas na menor densidade em função do menor sombreamento das folhas, o que gerou folhas mais espessas. 
Esses resultados divergem dos obtidos por Duarte \& Peil (2010) em melão tipo gália, que não verificaram alterações nas características vegetativas AF, AFE e teor de massa seca na fração vegetativa, caule e folhas em função da variação da densidade de plantas de 1,7 até 3,0 plantas $/ \mathrm{m}^{2}$. Peil \& López-Gálvez (2002), ao contrário, observaram que o aumento da densidade de plantas em pepino reduziu a biomassa da parte aérea, o número e massa de frutos por planta. Segundo os autores, mudanças na densidade de cultivo interferem no crescimento vegetativo e reprodutivo das plantas, uma vez que afetam a penetração de radiação solar no interior do dossel e, com isso, a sua taxa fotossintética.

\section{Características produtivas}

Os maiores valores para MMF, CMF e PT, foram obtidos no sistema de condução onde as plantas foram conduzidas com duas hastes e um fruto (S3), não diferindo significativamente do sistema S2 (Tabela 2). Resultados semelhantes foram obtidos por Watanabe et al. (2001) no cultivo de melancia no sistema vertical, onde a condução das plantas com duas hastes e um fruto promoveu aumento da massa média do fruto em comparação às conduzidas com uma haste. Nogueira (2008) também constatou que plantas conduzidas com uma haste e um fruto conduzido no ramo secundário produziram frutos maiores em relação às plantas conduzidas com uma haste e um fruto conduzido no ramo principal.

Os DMF foram significativamente semelhantes entre os sistemas S1 e S2 e inferiores ao sistema S3 (Tabela 2), concordando com Gualberto et al. (2001), cujo diâmetro do melão rendilhado foi superior quando as plantas foram conduzidas com duas hastes em relação às plantas conduzidas com uma haste.

A MMF, CMF e DMF foram superiores na menor densidade de plantas $\left(2,4\right.$ plantas $\left./ \mathrm{m}^{2}\right)$. Na maior densidade houve aumento de $75,8 \%$ na produtividade total, apesar da massa dos frutos ter sido reduzida em $12,1 \%$ (Tabela 2 ). Esse resultado corrobora com os obtidos por Watanabe et al. (2003), onde a redução do espaçamento entre plantas de 90 para $30 \mathrm{~cm}$, resultou em incremento de $54,8 \%$

Tabela 3. Teor de sólidos solúveis (SS), acidez titulável (AT), teor de ácido ascórbico (AA), pH e relação SS/AT da polpa dos frutos de minimelancia 'Smile' em função do sistema de condução (S) e da densidade de plantas (D) \{soluble solids (SS), titratable acidity (AT), ascorbic acid (AA), $\mathrm{pH}$ and the relation between soluble solids and titratable acidity (SS/ AT) of fruits pulp of mini watermelon 'Smile' pulp depending on the conduction height (A) and plant density (D) $\}$. Piracicaba, ESALQ, 2008/2009.

\begin{tabular}{|c|c|c|c|c|c|}
\hline Tratamentos & $\begin{array}{c}\text { SS } \\
\left({ }^{\circ} \text { Brix }\right)\end{array}$ & $\begin{array}{c}\text { AT ( } \% \text { ac. } \\
\text { citrico) }\end{array}$ & $\begin{array}{c}\mathrm{AA} \\
(\mathrm{mg} / \mathbf{1 0 0} \mathrm{g})\end{array}$ & pH & SS/AT \\
\hline \multicolumn{6}{|c|}{$\mathrm{S}$ (sistema de condução) ${ }^{1}$} \\
\hline S1 & $11,00 \mathrm{a}$ & 0,17 a & $8,47 \quad a b$ & $5,69 \mathrm{~b}$ & 64,21 a \\
\hline $\mathrm{S} 2$ & $10,45 \mathrm{~b}$ & $0,15 \mathrm{~b}$ & 9,21 a & 5,82 a & 68,78 a \\
\hline S3 & $10,55 \mathrm{~b}$ & 0,19 a & $7,47 \quad b$ & $5,53 \mathrm{c}$ & $57,45 \mathrm{~b}$ \\
\hline \multicolumn{6}{|c|}{$\mathrm{D}\left[\right.$ densidade de plantas $\left.\left(\mathrm{pl} / \mathrm{m}^{2}\right)\right]$} \\
\hline 4,8 & 10,69 a & $0,16 \mathrm{~b}$ & 8,37 a & 5,70 a & $66,05 \mathrm{a}$ \\
\hline 2,4 & $10,65 \mathrm{a}$ & 0,18 a & 8,40 a & 5,66 a & $60,92 \mathrm{~b}$ \\
\hline CV (\%) & 2,60 & 6,20 & 13,82 & 1,58 & 7,06 \\
\hline
\end{tabular}

Médias seguidas pela mesma letra na coluna não diferem entre si pelo teste de Tukey a 5\% (means followed by the same letter in the column do not differ by Tukey test at $5 \%$ ); ${ }^{1} \mathrm{~S} 1=$ plantas conduzidas com uma haste e um fruto por planta conduzido na haste principal; $\mathrm{S} 2=$ plantas conduzidas com uma haste e um fruto por planta conduzido na haste secundária; e $\mathrm{S} 3=$ plantas conduzidas com duas hastes e um fruto por planta conduzido na haste principal $(\mathrm{S} 1=$ plants conducted with one stem and one fruit per plant attached on the main stem; $\mathrm{S} 2=$ plants trained with one stem and one fruit per plant attached to the secondary stem, and S3= plants conducted with two stems per plant and one fruit attached to the main stem).

na produtividade e redução de $51,5 \%$ no peso médio do fruto de minimelancia cultivada no sistema vertical. Kultur et al. (2001) obtiveram aumento de $45,1 \%$ na produtividade e redução de $9,6 \%$ no peso médio dos frutos em plantas de meloeiro cultivadas com $35 \mathrm{~cm}$ de espaçamento entre plantas em comparação com plantas no espaçamento de $70 \mathrm{~cm}$.

A relação entre o aumento da produtividade e redução da massa média dos frutos com o aumento da densidade de plantas também foi observada em melancia cultivada no sistema rasteiro por outros autores (Goreta et al., 2005). No cultivo de melão, Ban et al. (2006), Gualberto et al. (2001) e Resende \& Costa (2003) também observaram redução significativa no peso médio dos frutos acompanhado de aumento na produtividade, quando o espaçamento entre plantas foi reduzido. Nunes et al. (2008), por outro lado, constataram que o aumento da densidade de plantas, além de ter resultado em aumento da produtividade, não diminuiu o peso médio dos frutos.

A diminuição do peso dos frutos pode resultar em redução da produtivi- dade comercial. Resende et al. (2006) observaram esse fato no cultivo de melancia 'Crimson Sweet', onde, apesar de ter resultado em maior produtividade total, a redução do espaçamento entre plantas de 80 para $40 \mathrm{~cm}$ causou aumento de $134 \%$ na produtividade de frutos refugos e redução de $30 \%$ na produtividade comercial.

Para o IFF, os sistemas de condução S1 e S3 (onde os frutos foram conduzidos na haste principal) foram semelhantes entre si e inferiores ao S2, indicando que os frutos produzidos nos ramos secundários (S2) foram mais alongados que os produzidos nos ramos principais (Tabela 2).

As densidades de cultivo, por sua vez, não influenciaram o IFF (Tabela 2). Resende \& Costa (2003) também não constataram efeito do espaçamento entre plantas sobre essa característica em melão. Grangeiro et al. (1999) entretanto, observaram que o aumento da densidade de plantio torna o fruto de melão amarelo mais arredondado. $\mathrm{O}$ índice de formato do fruto é uma importante característica para a cultura do melão, pois interfere na sua comercialização, 
uma vez que altera a quantidade de frutos por embalagem. Para minimelancia, esse índice ainda não é levado em consideração, mas futuramente poderá se tornar relevante, devido ao elevado valor agregado dessa hortaliça.

\section{Características físico-químicas dos frutos}

Não houve interação significativa entre os sistemas de condução e as densidades para as características físico-químicas dos frutos.

A maior concentração de ácido ascórbico na polpa do fruto $(9,21 \mathrm{mg} / 100$ g) foi obtida pelas plantas no sistema $\mathrm{S} 2$, em relação ao sistema S3 (Tabela 3 ). Os valores de ácido ascórbico encontrados nesse estudo foram superiores aos obtidos por Proietti et al. (2008) em minimelancia.

O teor de sólidos solúveis totais foi superior no sistema de condução $\mathrm{S} 1$, onde as plantas foram conduzidas com uma haste e um fruto fixado na haste principal, com valor de $11,0^{\circ}$ Brix (Tabela 3), contrariando os resultados encontrados por Watanabe et al. (2001) em minimelancia. Estes autores observaram aumentos nos teores de sólidos solúveis nos frutos provenientes de plantas conduzidas com duas hastes em comparação aos teores encontrados nos frutos das plantas cultivadas com uma haste. Os teores de sólidos solúveis encontrados nos frutos de melancia desse estudo foram superiores aos encontrados por Nogueira (2008) em cultivo realizado em casa-de-vegetação utilizando o mesmo material genético.

Os maiores valores de acidez titulável foram alcançados pelos frutos produzidos nos sistemas de condução S1 e S3 com 0,17 e 0,19\% de ácido cítrico, respectivamente (Tabela 3 ). Esse resultado pode estar relacionado ao período de desenvolvimento dos frutos. A polinização das flores dos tratamentos S1 e S3 ocorreu 8 dias antes do tratamento S2, o que antecipou a maturação dos frutos. A acidez titulável de frutos de melancia tende a aumentar até seu completo desenvolvimento fisiológico, quando então começa a decrescer com o processo de amadurecimento, devido ao seu uso como substrato no processo respiratório ou de sua conversão em açúcares (Chitarra \& Chitarra, 2005).
Esse fato foi constatado em experimento realizado por Almeida et al. (2010), onde a acidez titulável foi crescente e atingiu o máximo aos 20 dias de desenvolvimento, em seguida reduziu $41 \%$ até os 30 dias.

$\mathrm{O}$ maior $\mathrm{pH}$, por sua vez, foi alcançado no sistema S2 com valor de 5,82, sendo superior aos apresentados pelos sistemas S1 e S3, com 5,69 e 5,53, respectivamente (Tabela 3 ). Esses valores condizem com os obtidos por Proietti et al. (2008) em minimelancia.

Os sistemas de condução S1 e S2, onde as plantas foram conduzidas com uma haste, proporcionaram as maiores relações SS/AT dos frutos, apresentando valores de 64,21 e 68,78, significativamente superiores ao sistema S3 (plantas com duas hastes), com valor de 57,45 (Tabela 3). A relação SS/AT dos frutos é uma característica que expressa a razão entre o teor de sólidos solúveis e a acidez titulável. Como o amadurecimento, em geral, conduz ao aumento no teor de açúcares e redução da acidez (Chitarra \& Chitarra, 2005), os valores mais elevados para a relação SS/AT demonstram que os frutos são mais doces, característica desejável na qualidade dos frutos. Valores semelhantes tanto para a relação SS/AT como para o $\mathrm{pH}$, acidez titulável e teor de sólidos solúveis, em melancia, foram obtidos por Andrade Junior et al. (2006).

Nogueira (2008), por sua vez, não observou diferenças significativas entre os sistemas de condução vertical das hastes (plantas com frutos mantidos na haste principal ou secundária, com poda das hastes secundárias ou com crescimento livre) de plantas de minimelancia 'Smile' sobre o teor de sólidos solúveis, acidez titulável, pH e relação SS/AT da polpa dos frutos. Os valores obtidos pelo autor para a acidez titulável e $\mathrm{pH}$ foram semelhantes, enquanto que para o teor de sólidos solúveis e relação SS/ AT foram inferiores aos apresentados nesse trabalho.

O espaçamento entre plantas influenciou a acidez titulável, apresentando maior valor na menor densidade de plantas. Consequentemente, isso reduziu a relação $\mathrm{SS} / \mathrm{AT}$ dos frutos, uma vez que o teor de sólidos solúveis (SS) não sofreu a influência do espaçamento entre plantas (Tabela 3). A concentração de ácido ascórbico e o pH da polpa dos frutos não foram influenciados pela densidade de plantas.

Esses resultados estão de acordo com os obtidos por Goreta et al. (2005) e Bastos et al. (2008) em melancia. Mendlinger (1994), porém, constatou redução do teor de sólidos solúveis com o aumento da densidade de plantas de meloeiro. Segundo o autor, o aumento da densidade de plantas promoveu redução da área foliar e aumento do índice de área foliar, o que causou maior sombreamento das folhas, levando à redução da fotossíntese das plantas e do teor de sólidos solúveis nos frutos.

Baseado nos resultados obtidos, a condução das plantas com duas hastes e frutos fixados na haste principal (S3) apresenta vantagens, pois proporciona maior rendimento em comparação ao $\mathrm{S} 1$, maior precocidade em relação ao S2 e características físico-químicas dos frutos adequadas para a comercialização. Para esse sistema de condução, a densidade de cultivo de 4,8 plantas $/ \mathrm{m}^{2}$ eleva a produtividade em aproximadamente duas vezes a alcançada pela densidade de 2,4 plantas $/ \mathrm{m}^{2}$.

\section{REFERÊNCIAS}

ALMEIDA D. 2006. Manual de culturas horticola. Lisboa: Ed. Presença, v.2, 325 p.

ALMEIDA MLB; SILVA GG; ROCHA RHC; MORAIS PLD; SARMENTO JDA. 2010. Caracterização físico-química de melancia 'quetzali' durante o desenvolvimento. Revista Caatinga 23: 28-31.

ANDRADE JUNIOR AS; DIAS NS; FIGUEIREDO JUNIOR LGM; RIBEIRO VQ; SAMPAIO DB. 2006. Produção e qualidade de frutos de melancia à aplicação de nitrogênio via fertirrigação. Revista Brasileira de Engenharia Agrícola e Ambiental 10: 836-841.

BAN D; GORETA S; BOROSIC J. 2006. Plant spacing and cultivar affect melon growth and yield components. Scientia Horticulturae 109: 238-243.

BASTOS FGC; AZEVEDO BM; REGO JL; VIANA TVA; D’ÁVILA JHT. 2008. Efeitos de espaçamentos entre plantas na cultura da melancia na Chapada do Apodi, Ceará. Revista Ciência Agronômica 39: 240-244.

CARVALHO CRL; MANTOVANI DMB; CARVALHO PRN; MORAES RMM. 1990. Análises químicas de alimentos: manual técnico. Campinas: ITAL. $121 \mathrm{p}$.

CHITARRA MIF; CHITARRA AB. 2005. Póscolheita de frutas e hortaliças: fisiologia e 
manuseio. 2. ed. Lavras:UFLA. 785 p.

DUARTE TS; PEIL RMN. 2010. Relações fonte:dreno e crescimento vegetativo do meloeiro. Horticultura Brasileira 28: 271-276.

DUARTE TS; PEIL RMN; MONTEZANO EM. 2008. Crescimento de frutos do meloeiro sob diferentes relações fonte:dreno. Horticultura Brasileira 26: 342-347.

FIESP; ITAL. 2010. Brasil Food Trends 2002. São Paulo: FIESP/ITAL. Disponível em http:// www.brasilfoodtrends.com.br. Acessado em 30 de janeiro de 2014.

GORETA S; PERICA S; DUMICIC LB; ZANIC K. 2005. Growth and yield of watermelon on polyethylene mulch with different spacings and nitrogen rates. Hortscience 40: 366-369.

GRANGEIRO LC; PEDROSA JF; BEZERRA NETO F; NEGREIROS MZ. 1999. Qualidade de híbridos de melão amarelo em diferentes densidades de plantio. Horticultura Brasileira 17: 110-113.

GUALBERTO R; RESENDE FV; LOSASSO PHL. 2001. Produtividade e qualidade do melão rendilhado em ambiente protegido, em função do espaçamento e sistema de condução. Horticultura Brasileira 19: 240-243.

IBGE. 2014. Taxa de fecundidade total, por grupos de anos de estudo das mulheres - 1970 a 2005. Disponível em http://seriesestatisticas. ibge.gov.br/series.aspx?no=10\&op $=0 \&$ vcodig $\mathrm{o}=\mathrm{CD} 108 \& \mathrm{t}=$ taxa-fecundidade-total-gruposanos-estudo. Acessado em 25 de fevereiro de 2014.

KULTUR F; HARRISON HC; STAUB JE. 2001. Spacing and genotype affect fruit sugar concentration, yield, and fruit size of muskmelon. Hortscience 36: 274-278.
MAROUELLI WA. 2008. Tensiômetros para controle de irrigação em hortaliças. Brasília, DF: Embrapa Hortaliças. 15 p. (Circular Técnica, 57).

MENDLINGER S. 1994. Effect of increasing plant density and salinity on yield and fruit quality in muskmelon. Scientia Horticulturae 57: 41-49.

NOGUEIRA CCP. 2008. Fertirrigação em minimelancia (Citrullus lanatus) tutorada em ambiente protegido. Piracicaba: ESALQ. 74p. (Tese doutorado).

NUNES GHS; PEREIRA EWL; SALES JUNIOR R; BEZERRA NETO F; OLIVEIRA KC, MESQUITA LX. 2008. Produtividade e qualidade de frutos de melão pele-de-sapo em duas densidades de plantio. Horticultura Brasileira 26: 236-239.

PAPADOPOULOS AP. 1994. Growing greenhouse seedless cucumbers in soil and in soilless media. Ottawa: Agriculture and Agri-Food Canada. 126 p. (Agriculture and Agri-Food Canada Publication, 1902/E).

PEIL RM; LOPÉZ-GALVÉZ J. 2002. Fruit growth and biomass allocation to the fruits in cucumber: effect of plant density and arrangement. Acta Horticulturae 588: 75-80.

PEIL RMN. 2000. Radiación solar interceptada y crescimiento del pepino cultivado em NFT. Almería: Universidade de Almería. 210p. (Tese doutorado).

PROIETTI S; ROUPHAEL Y; COLLA G; CARDARELLI M; AGAZIO M; ZACCHINI M; REAE; MOSCATELLO E; BATTISTELLI A. 2008. Fruit quality of mini-watermelon as affected by grafting and irrigation regimes. Journal of the Science of Food and Agriculture
88: $1107-1114$

PURQUERIO LFV; MELO, PCT. 2011. Hortaliças pequenas e saborosas. Horticultura Brasileira 29: 1-1.

RESENDE GM; COSTA ND. 2003. Produção e qualidade do melão em diferentes densidades de plantio. Horticultura Brasileira 21: 690694.

RESENDE GM; COSTA ND; DIAS RCS. 2006. Densidade de plantio na cultura da melancia no vale do São Francisco. Petrolina: EMBRAPA. 4p. (Comunicado Técnico 125).

SCHVAMBACH JL; ANDRIOLO JL; HELDWEIN AB. 2002. Produção e distribuição da matéria seca do pepino para conserva em diferentes populações de plantas. Ciência Rural 32: 35-41.

SILVA HR; CARRIJO OA; REIS NVB; MAROUELLI WA. 1998. Competição de cultivares de pepino tipo 'Japones' sob cultivo protegido e a campo aberto. Horticultura Brasileira 16: 314.

WATANABE S; NAKANO Y; OKANO K. 2001. Relationships between total leaf area and fruit weight in vertically and horizontally trained watermelon [Citrullus lanatus (Thunb.) Matsum. et Nakai] plants. Journal of the Japanese Society for Horticultural Science 70: 725-732.

WATANABE S; NAKANO Y; OKANO K. 2003. Effect of planting density on fruit size, light-interception and photosynthetic activity of vertically trained watermelon [Citrullus lanatus (Thunb.) Matsum. et Nakai] plants. Journal of Japaneses Society for the Horticultural Science 72: 497-503. 